\title{
Penerapan Metode Demontrasi dalam Meningkatkan Hasil Belajar Pendidikan Agama Islam (PAI) Siswa Kelas XI SMA Negeri 1 Metro TA 2019/2020
}

\author{
Nurhasim \\ SMA Negeri 1 Metro \\ nur22hasim@gmail.com
}

\begin{abstract}
Problems in the implementation of learning cause students' learning outcomes are not good. As for example, the implementation of learning is still centered on the teacher, is conventional by using the lecture system in full, the emphasis is not on facts and information, but rather emphasizes on memorization, attaches more importance to the content than the process, and is less directed at meaningful and functional learning for the lives of students. The learning process that does not involve students in the real world and does not realize interaction between students, making it less interesting, boring, students become passive, as a result of which students can not master the material well. To overcome all of that, researchers applied new media as a way to increase students' learning interest, namely by using demonstration methods. The issue was discussed through class action research conducted through two cycles. Research data obtained through observation in the classroom and documentation of the results of actions taken as well as data from class teachers. From the results of the study obtained an increase in each cycle, namely on the increase in the average grade of students in the pre-cycle is 66.77 in cycle I: 75.00 and 80.00 in cycle II. The percentage of students' learning completion also increased, namely $62.06 \%$ in pre-cycle, $79.31 \%$ in cycle I, and $100 \%$ in cycle II. Thus, the increase in learning completion from pre-cycle to cycle I after improvement was $17.25 \%$, and increased from cycle I to cycle II by $20.69 \%$.
\end{abstract}

Keywords: Demonstration Method, PTK, Funeral Management, PAI

\begin{abstract}
ABSTRAK
Permasalahan dalam pelaksanaan pembelajaran menyebabkan hasil belajar siswa kurang baik. Seperti misalnya pelaksanaan pembelajaran masih berpusat pada guru, bersifat konvensional dengan mengunakan sistem ceramah secara penuh, penekankannya tidak pada fakta dan informasi, tetapi lebih menekankan pada hafalan, lebih mementingkan isi dari pada proses, dan kurang diarahkan pada pembelajaran yang bermakna dan berfungsi bagi kehidupan siswa. Proses pembelajaran yang tidak melibatkan siswa dalam dunia nyata serta kurang mewujudkan interaksi antar siswa, sehingga kurang menarik, membosankan, peserta didik menjadi pasif, akibatnya peserta didik tidak bisa menguasai materi dengan baik. Untuk mengatasi itu semua, peneliti menerapkan media baru sebagai cara untuk meningkatkan minat belajar siswa, yaitu dengan mengunakan metode demonstrasi. Permasalahan tersebut dibahas melalui penelitian tindakan kelas yang dilakukan melalui dua siklus. Data penelitian diperoleh melalui observasi di kelas dan dokumentasi hasil tindakan yang dilakukan maupun data dari guru kelas. Dari hasil penelitian tersebut
\end{abstract}


diperoleh peningkatan pada setiap siklusnya, yaitu pada kenaikan nilai rata-rata siswa pada pra siklus yaitu 66,77 pada siklus I: 75,00 dan 80,00 pada siklus II. Persentase ketuntasan belajar siswa juga mengalami peningkatan, yaitu $62,06 \%$ pada pra siklus, $79,31 \%$ pada siklus I, dan $100 \%$ pada siklus II. Dengan demikian kenaikan ketuntasan belajar dari pra siklus ke siklus I setelah dilakukan perbaikan sebesar 17,25\%, dan meningkat dari siklus I kesiklus II sebesar 20,69\%.

Kata Kunci: Metode Demonstrasi, PTK, Pengurusan Jenazah, PAI

\section{PENDAHULUAN}

Konseptualisai terhadap pendidikan dengan pendekatan spiritual menjadi hal yang sangat penting dimasa kini, karena ternyata konsep dan teori-teori pendidikan yang ada belum atau tidak mampu menjawab tantangan di era globalisasi dengan segala anomalinya. Belum atau tidak mampu secara aktual menanggulangi tingginya dekadensi moral. Fakta kerusakan moral para remaja membuktikan bahwa pendidikan yang hanya menitikberatkan pada aspek intelektualitas semata, dan menafikan aspek-aspek moralspiritual dari pendidikan adalah kemampuannya secara intektual bagus tetapi sering menunjukkan prilaku orng yang tidak punya etika sopan santun, tawuran antar pelajar, budaya free sex, kondomisasi, aborsi, dan kehamilan di luar nikah sudah menjadi suatu hal yang biasa. Budaya tersebut menjadi tidak terbendung, mengingat derasnya arus globalisasi informasi melalui media massa, tv dan internet, yang masuk ke Indonesia, hampir tiap kawasan pelosok pedesaan, tiap rumah diruang keluarga dan bahkan tiap sekolah termasuk di SMA Negri 1 Metro Lampung.

Terkadang agar terlihat beda dan berkelas dalam pandangan masyarakat, maka menjadikan sebuah kebanggaan hati ketika melihat corak dan karakteristik model pendidikan barat yang unik dan maju, walaupun sesungguhnya tidak bisa mengesampingkan kebobrokan moral dan etika yang menghancurkan sendi-sendi kehidupan sosial manusia yang luhur, dan menghilangkan fitrah asal manusia itu sendiri.

Dalam UU No 20 Tahun 2003 Bab II Pasal 3 disebutkan: "Pendidikan nasional berfungsi mengembangkan kemampuan dan membentuk watak serta peradaban bangsa yang bermartabat dalam rangka mencerdaskan kehidupan bangsa, bertujuan untuk berkembangnya potensi peserta didik agar menjadi manusia yang beriman dan bertakwa kepada Tuhan Yang Maha Esa, berakhlak mulia, sehat, berilmu, cakap, kreatif, mandiri, dan menjadi warga negara yang demokratis serta bertanggung jawab." (Undang-undang Sisdiknas. 2003:7)

Tujuan pendidikan mencakup tiga dimensi. Yaitu dimensi ketuhanan, pribadi dan sosial. Artinya, pendidikan bukan diarahkan pada pendidikan yang sekuler, bukan pada 
pendidikan individualistik, dan bukan pula pada pendidikan sosialistik. Tetapi pendidikan di Indonesia diarahkan pada pendidikan mencari keseimbangan antara ketuhanan, individu dan sosial. Sehingga generasi yang terbentuk menjadi generasi yang mempunyai karakterisitik sendiri sebagaimana yang sering disebut dalam istilah pendidikan karakter. Jadi pendidikan di Indonesia tidak memisahkan antara agama dan pendidikan, namun keduanya disandingkan untuk mencapai generasi yang memiliki keluhuran budi, taat dalam mengabdi kepada Tuhan, berpengatahuan luas dan cerdas serta dapat menciptakan suasana damai dan menyenagkan bagi sesama dan alam sekitar.

Menurut Marimba, dalam Tafsir pendidikan merupakan bimbingan atau pimpinan secara sadar oleh pendidik terhadap perkembangan jasmani dan rohani anak didik menuju terbentuknya kepribadian utama (Tafsir, 2014: 46). Abdul Fattah Jalal mengungkapkan tujuan dari pendidikan Islam adalah terwujudnya manusia sebagai hamba Allah. Tujuan itu adalah untuk semua manusia. Jadi, menurut Islam pendidikan harus menjadikan seluruh manusia menjadikan manusia yang menghambakan diri atau selalu beribadah kepada Allah.

Sudah jelas bahwa peran pendidikan sangatlah penting bagi kehidupan manusia yang akan membawa manusia menuju kearah taqwa dan perdamaian baik dalam kehidupan di dunia yang hidup berdampingan dengan makhluk lain, maupun menjadi hamba Allah yang bertaqwa dan selalu beriman kepada Allah. Tidak hanya pendidikan secara umum saja yang penting, namun Pendidikan Agama Islam disekolahan tidak kalah penting terutama disekolah-sekolah umum.

Pendidikan Agama Islam menjadi salah satu mata pelajaran wajib bagi seluruh sekolah yang ada di Indonesia. Pendidikan Agama Islam dalam sistem pendidikan nasional memiliki peran yang sangat penting karena melalui mata pelajaran Pendidikan Agam Islam inilah peserta didikdapat mengetahui agama Islam lebih jauh. Karena memiliki peran penting, maka dari itu perlu dilakukan inovasi dalam pembelajaran yang memungkinkan peserta didik dapat berperan aktif dalam proses belajar mengajar di mana peserta didikakan merasa senang dan tidak merasa bosan dalam penyampaian Pendidikan Agama Islam (PAI) materi pembelajaran secara maksimal dan peserta didikdapat memahami materi diberikan. Namun kenyataan dilapangan menunjukkan bahwa peserta didik kurang termotivasi untuk belajar agama karena proses pembelajaran yang kurang inovasi dan hanya menggunakan metode pembelajaran yang monoton. Perserta didik kurang tertarik dan termotovasi untuk aktif dalam kegiatan pembelajaran sehingga materi kurang dipahami oleh peserta didik. 
Untuk menumbuhkan semangat motivasi peserta didik dalam pembelajaran Pendidikan Agama Islam, harus ada pembelajaran yang aktif, kreatif, menarik dan tidak membosankan. Peneliti memilih untuk menerapkan metode Demonstrasi yaitu cara penyajian pembelajaran dengan memperagakan atau mempertujukan kepada peserta didik suatu proses, situasi atau benda tertentu yang sedang dipelajari baik dalam bentuk tiruan maupun sebenarnya yang dipertunjukan oleh guru atau sumber lain yang ahli dalam proses dalam topik pembahasan (Mulyani Sumantri dalam Roetiyah 2001: 82)

Fathurrohman P. (2007:98) mengemukakan bahwa tujuan penerapan metode demonstrasi adalah untuk memperjelas pengertian konsep dan memperlihatkan cara melakukan sesuatu atau proses terjadinya sesuatu seperti:

a) Mengajar peserta didiktentang suatu tindakan, proeses, atau prosedur keterampilan-keterampilan fisik dan motorik.

b) Mengembangkan kemampuan pengamatan pendengaran dan penglihatan para peserta didiksecara bersama- sama.

c) Mengkonkritkan informasi yang disajikan kepada siswa.

Dengan kata lain, metode demonstrasi dapat membantu peserta didik dalam mengatasi kesulitan belajar dan pemahaman pelajaran yang diajarkan oleh guru sedangkan guru merupakan komponen dalam belajar mengajar dan berinteraksi langsung dengan siswa. Guru mempunyai peranan sangat penting terhadap terciptanya proses pembelajran yang dapat mengantarkan peserta didikketujuan pembelajaran yang telah ditetapkan.

Aktivitas belajar peserta didik yang rendah sering kali juga menyebabkan pemahaman dan pengusaan materi pembelajran menjadi berkurang. Jika hal ini dibiarkan terjadi terus menerus maka tidak bisa dipungkiri akan berpengaruh pada hasil belajar siswa. Kerana kurangnya aktivitas belajar maka hasil belajar juga menjadi kurang baik bahkan bisa menjadi rendah.

Agar peserta didikberperan sebagai pelaku dalam kegiatan belajar, maka guru hendaknya merencanakan proses pembelajaran yang menuntut peserta didikbanyak melakukan aktivitas belajar sehingga mampu dalam mempelajari suatu pelajaran dan tercermin dari hasil belajarnya. Hasil belajar mempunyai peranan penting dalam proses pembelajaran.

Salah satu cara untuk membangkitkan aktivitas dan hasil belajar peserta didikdalam proses pembelajaran, guru sebagai tenaga pendidik perlu mencari atau mengganti metode pembelajaran yang tepat untuk itu perlu dipilih metode pembelajaran yang tepat dan menarik aktivitas siswa. Banyak metode pembelajaran yang digunakan dalam pelajaran Pendidikan Agama Islam (PAI). 
Dari hasil observasi di SMA N 1 Metro diperoleh bahwa rata-rata hasil belajar Pendidikan Agama Islam (PAI) kelas XI masih tergolong rendah karena rata-rata peserta didik belum mencapai taraf ketuntasan yaitu kurang dari Kreteria Ketuntasan Minimal (KKM) 75 sehingga, masih diperlukan perbaikan.

Untuk meningkatkan aktivitas dan hasil belajar mata pelajaran Pendidikan Agama Islam (PAI) maka penyajian pembelajarannya harus menarik. Sehingga peserta didik termotivasi untuk belajar. Diperlukan metode pembelajaran interaktif dimana guru yang pada saat ini menggunakan metode ceramahdan lebih banyak memberikan peran kepada peserta didiksebagai subjek belajar, guru mengutamakan proses dari pada hasil. Salah satu cara adalah dengan menunggunakan pembelajaran demonstrasi. Dalam hal ini peserta didikdituntut untuk dapat berfikir, memecahkan masalah dan belajar untuk mengaplikasikan pengetahuan, konsep dan keterampilan kepada peserta didik yang membutuhkan dan peserta didikmerasa senang untuk menyumbangkan pendapatnya kepada anggota kelompoknya.

\section{METODE PENELITIAN}

Penelitian yang digunakan dalam penelitian ini adalah penelitian tindakan kelas (PTK). Menurut Arikunto, Penelitian Tindakan Kleas merupakan percermatan dalam bentuk tindakan kelas yang senagaja dimunculkan dan terjadi dalam sebuah kelas secara bersamaan (Suyadi, 2010:18). Rancangan penelitian yang ditetapkan adalah penelitian tindakan kelas mengenai Peningkatan Hasil Belajar Pendidikan Agama Islam (PAI) materi Pengurusan Jenazah melalui metode Demosntrasi pada peserta didik kelas XI SMA N 1 Metro dengan subjek berjumlah 18 siswa.

Adapun langkah-langkah dalam penelitian ini adalah perencanaan, pelaksanaan, pengamatan, dan refleksi.

Untuk mengetahui peningkatan prestasi belajar peserta didik, peneliti menggunakan statistik deskriptif dengan mencari persentase dari hasil belajar peserta didik, sebagaimana dirumuskan:

$$
\bar{X}=\frac{\sum x i}{N}
$$

Keterangan :

$\bar{X} \quad$ : Nilai Rata-rata

$\sum x i \quad$ Jumlah Nilai Siswa

$\mathrm{N} \quad$ : Jumlah Siswa 


\section{HASIL DAN PEMBAHASAN}

\section{HASIL}

Berdasarkan observasi sebelum melakukan penelitian tindakan kelas, peneliti menyampaikan materi Pengurusan Jenazah kepada siswa dengan menggunakan metode Demonstrasi. Dari dokumentasi sebelum penerapan penggunaan metode demonstrasi, diperoleh prestasi belajar peserta didik yang masih jauh dari harapan, karena masih banyak peserta didik yang prestasi belajarnya di bawah KKM. Ketuntasan yang harus dicapai Pendidikan Agama Islam (PAI) yaitu 75. Inilah yang menjadi acuan pelaksanaan penelitian tindakan kelas di kelas XI IPA 3 SMA N 1 Metro. Berikut daftar nilai pra siklus peserta didikkelas XI IPA3 SMA N 1 Metro.

Tabel 1

Daftar Nilai Pra Siklus

\begin{tabular}{|l|l|c|c|c|}
\hline No & & \multicolumn{1}{|c|}{ Nama } & \multicolumn{2}{c|}{ Neterangan } \\
\hline & & & Tuntas & Tidak Tuntas \\
\hline 1 & ADELLIA PRATIWI & 60 & & $\checkmark$ \\
\hline 2 & AMELIYA NADA KHANA & 65 & & $\checkmark$ \\
\hline 3 & ANGGRAENI SIWI HAPSARI & 75 & $\checkmark$ & \\
\hline 4 & ANISA FAUJIA & 65 & & $\checkmark$ \\
\hline 5 & AR-RAFI RAHADIAN & 65 & & $\checkmark$ \\
\hline 6 & DEA HIMALIA PUTRI & 75 & $\checkmark$ & $\checkmark$ \\
\hline 7 & DINDA FALAIZA HARDWITA & 65 & & $\checkmark$ \\
\hline 8 & FAHRI DEAN ALVITO & 70 & & $\checkmark$ \\
\hline 9 & FARHAN BAROO ROZZAN & 70 & & $\checkmark$ \\
\hline 10 & FAUZI IKHSAN & 75 & $\checkmark$ & $\checkmark$ \\
\hline 11 & FIRIYAL CHASNA SEFIA PUTRI & 65 & & $\checkmark$ \\
\hline 12 & FITROH AGUNG DIMAS TETUKO & 65 & & $\checkmark$ \\
\hline 13 & JIHAN ALFIRA FITRIANA & 75 & $\checkmark 5$ & $\checkmark$ \\
\hline 14 & M. RAMANDA PUTRA & 65 & & $\checkmark$ \\
\hline 15 & MADYA RAHMANDA WANANTA & 75 & & $\checkmark$ \\
\hline 16 & MERI ANDANI & 65 & & $\checkmark$ \\
\hline 17 & MUHAMMAD ABIZAR RIZKY & 65 & \\
\hline 18 & REGITA AYUNI MUTHIA CANSA & 75 & & $\checkmark$ \\
\hline
\end{tabular}




\begin{tabular}{|l|l|}
\hline KKM & 75 \\
\hline RATA-RATA KELAS & 71.11 \\
\hline TUNTAS & 6 \\
\hline TIDAK TUNTAS & 12 \\
\hline PRESENTASE KETUNTASAN & $34 \%$ \\
\hline
\end{tabular}

Dari tabel di atas menunjukkan hasil belajar pra-siklus dari 18 siswa. Nilai tertinggi yang diperoleh peserta didik adalah 75 dan nilai terendah adalah 60. Nilai rata-rata kelas yang dicapai yaitu 71.11. Pada prasiklus jumlah peserta didik yang tuntas yaitu 6 peserta didik dan yang tidak tuntas ada 12 siswa.

Pada tahap selanjtnya peneliti menerapkan pembelajaran pada materi jenazah dengan menggunakan metode demonstrasi. Pada penerapan metode ini peneliti melakukan empat tahapan penelitian yaitu: perencanaan, tindakan, observasi dan refleksi. Adapun hasil dari penerapan metode tersebut adalah sebagai berikut:

Tabel 2

Nilai Siswa Siklus 1

\begin{tabular}{|l|l|c|c|c|}
\hline \multirow{2}{*}{ No } & \multicolumn{1}{|c|}{ Nama } & Nilai & \multicolumn{2}{|c|}{ Keterangan } \\
\cline { 3 - 5 } & & & Tuntas & Tidak Tuntas \\
\hline 1 & ADELLIA PRATIWI & 60 & $\checkmark$ & \\
\hline 2 & AMELIYA NADA KHANA & 65 & & $\checkmark$ \\
\hline 3 & ANGGRAENI SIWI HAPSARI & 75 & $\checkmark$ & $\checkmark$ \\
\hline 4 & ANISA FAUJIA & 65 & & $\checkmark$ \\
\hline 5 & AR-RAFI RAHADIAN & 65 & & $\checkmark$ \\
\hline 6 & DEA HIMALIA PUTRI & 75 & $\checkmark$ & \\
\hline 7 & DINDA FALAIZA HARDWITA & 65 & $\checkmark$ & \\
\hline 8 & FAHRI DEAN ALVITO & 70 & $\checkmark$ & \\
\hline 9 & FARHAN BAROO ROZZAN & 70 & $\checkmark$ & \\
\hline 10 & FAUZI IKHSAN & 75 & $\checkmark$ & \\
\hline 11 & FIRIYAL CHASNA SEFIA PUTRI & 65 & $\checkmark$ & \\
\hline 12 & FITROH AGUNG DIMAS TETUKO & 65 & $\checkmark$ & \\
\hline 13 & JIHAN ALFIRA FITRIANA & 75 & $\checkmark 5$ & \\
\hline 14 & M. RAMANDA PUTRA & 75 & $\checkmark$ & \\
\hline 15 & MADYA RAHMANDA WANANTA & & $\checkmark$ & \\
\hline
\end{tabular}




\begin{tabular}{|c|c|c|c|c|}
\hline 16 & MERI ANDANI & 65 & $\sqrt{ }$ & \\
\hline 17 & $\begin{array}{l}\text { MUHAMMAD ABIZAR RIZKY } \\
\text { PUTRA }\end{array}$ & 65 & & $\checkmark$ \\
\hline 18 & REGITA AYUNI MUTHIA CANSA & 75 & $\checkmark$ & \\
\hline \multicolumn{4}{|c|}{ KKM } & 75 \\
\hline \multicolumn{4}{|c|}{ RATA-RATA KELAS } & 75.00 \\
\hline \multicolumn{4}{|c|}{ TUNTAS } & 11 \\
\hline \multicolumn{4}{|c|}{ TIDAK TUNTAS } & 7 \\
\hline \multicolumn{4}{|c|}{ PRESENTASE KETUNTASAN } & $61 \%$ \\
\hline
\end{tabular}

Dari tablel di atas menunjukkan hasil belajar siklus I dari 18 siswa. Nilai tertinggi yang diperoleh peserta didik adalah 80 dan nilai terendah adalah 65 . Nilai rata-rata kelas yang dicapai yaitu: 7.5. Pada siklus I jumlah peserta didik yang tuntas yaitu 11 peserta didik dan yang tidak tuntas ada 7 siswa.

Pada tahap siklus II peneliti melanjutkan pembelajaran dengan menggunakan metode demonstrasi. Pada penerapan metode ini peneliti melakukan empat tahapan penelitian yaitu: perencanaan, tindakan, observasi dan refleksi. Adapun hasil dari penerapan metode tersebut adalah sebagai berikut:

Tabel 3

Nilai Siswa Siklus II

\begin{tabular}{|l|l|c|c|c|}
\hline \multirow{2}{*}{ No } & \multicolumn{1}{|c|}{ Nama } & Nilai & \multicolumn{2}{|c|}{ Keterangan } \\
\cline { 3 - 5 } & & & Tuntas & Tidak Tuntas \\
\hline 1 & ADELLIA PRATIWI & 60 & $\checkmark$ & \\
\hline 2 & AMELIYA NADA KHANA & 65 & $\checkmark$ & \\
\hline 3 & ANGGRAENI SIWI HAPSARI & 75 & $\checkmark$ & \\
\hline 4 & ANISA FAUJIA & 65 & $\checkmark$ & \\
\hline 5 & AR-RAFI RAHADIAN & 65 & $\checkmark$ & \\
\hline 6 & DEA HIMALIA PUTRI & 75 & $\checkmark$ & \\
\hline 7 & DINDA FALAIZA HARDWITA & 65 & $\checkmark$ & \\
\hline 8 & FAHRI DEAN ALVITO & 70 & $\checkmark$ & \\
\hline 9 & FARHAN BAROO ROZZAN & 70 & $\checkmark$ & \\
\hline 10 & FAUZI IKHSAN & 75 & $\checkmark$ & \\
\hline 11 & FIRIYAL CHASNA SEFIA PUTRI & 65 & $\checkmark$ & \\
\hline
\end{tabular}




\begin{tabular}{|c|c|c|c|c|}
\hline 12 & $\begin{array}{l}\text { FITROH AGUNG DIMAS } \\
\text { TETUKO }\end{array}$ & 65 & $\checkmark$ & \\
\hline 13 & JIHAN ALFIRA FITRIANA & 75 & $\checkmark$ & \\
\hline 14 & M. RAMANDA PUTRA & 65 & $\checkmark$ & \\
\hline 15 & $\begin{array}{l}\text { MADYA RAHMANDA } \\
\text { WANANTA }\end{array}$ & 75 & $\checkmark$ & \\
\hline 16 & MERI ANDANI & 65 & $\checkmark$ & \\
\hline 17 & $\begin{array}{l}\text { MUHAMMAD ABIZAR RIZKY } \\
\text { PUTRA }\end{array}$ & 65 & $\checkmark$ & \\
\hline 18 & REGITA AYUNI MUTHIA CANSA & 75 & $\checkmark$ & \\
\hline \multicolumn{4}{|c|}{ KKM } & 75 \\
\hline \multicolumn{4}{|c|}{ RATA-RATA KELAS } & 81,94 \\
\hline \multicolumn{4}{|c|}{ TUNTAS } & 18 \\
\hline \multicolumn{4}{|c|}{ TIDAK TUNTAS } & 0 \\
\hline \multicolumn{4}{|c|}{ PRESENTASE KETUNTASAN } & $100 \%$ \\
\hline
\end{tabular}

Tabel di atas menunjukkan hasil belajar siklus II dari 18 siswa. Nilai tertinggi yang diperoleh peserta didik adalah 95 dan nilai terendah adalah 75 . Nilai rata-rata kelas yang dicapai yaitu 81.94. Pada prasiklus jumlah peserta didik yang tuntas yaitu 18 peserta didikdan yang tidak tuntas ada 0 siswa. Dari uraian data tersebut dapat dilihat peningkatan hasil belajar yang singnifikan dan positif pada pembelajaran dengan menggunakan metode demonstrasi.

\section{PEMBAHASAN}

Dari hasil penelitian yang diperoleh berdasarkan data-data yang terkumpul, diketahui bahwa penggunaan metode pembelajaran Demonstrasi pada pembelajaran meteri jenazah dapat meningkatkan hasil belajar siswa. Dengan menggunakan metode demonstrasi dalam pembelajaran Pendidikan Agama Islam (PAI) yang dilaksanakan dalam penelitian tindakan kelas tersebut menunjukkan bahwa peserta didik dapat menerima materi pengurusan jenazah dengan baik. Hal ini dibuktikan dengan peningkatan hasil belajar peserta didikselama pelajaran berlangsung. Maka pembelajaran dengan menggunakan metode demonstrasi dapat dikatakan menjadi salah satu solusi untuk mencapai target yang telah ditentukan.

Berdasarkan hasil ulangan harian pada kondisi awal atau pra siklus, nilai rata-rata dari 18 peserta didik yaitu 71,11 dengan rincian 6 peserta didik mencapai KKM. dan 
dinyatakan tuntas, sedangkan 11 peserta didik yang belun mencapai KKM. dan dinyatakan belum tuntas. Berarti ketuntasan belajar peserta didik $=34 \%$

Hal tersebut dikarenakan guru dalam proses belajar mengajar masih menggunakan metode konvesional sehingga pembelajaran yang muncul kurang menarik peserta didikdan peserta didikmenjadi kurang aktif. Dengan demikian hasil belajar peserta didikkurang maksimal dan masih banyak yang belum mencapai Kriteria Ketuntasan Minimum (KKM). Melihat hal tersebut agar dapat meningkatkan hasil belajar peserta didikmaka peneliti melakukan penelitian tindakan kelas dengan menggunakan metode Demonstrasi.

Dari penelitian tersebut menunjukkan bahwa terjadi peningkatan hasil belajar peserta didik, hal ini dapat dilihat dari nilai -nilai tes formatif yang diperoleh peserta didik disetiap siklusnya seperti pada tabel sebagai berikut:

Tabel 4

Nilai Keseluruhan Siklus

\begin{tabular}{|c|c|c|c|c|}
\hline \multirow[t]{2}{*}{ No } & \multirow[t]{2}{*}{ Nama } & \multicolumn{3}{|c|}{ Siklus } \\
\hline & & Pra Siklus & Siklus I & Siklus II \\
\hline 1 & ADELLIA PRATIWI & 60 & 75 & 75 \\
\hline 2 & AMELIYA NADA KHANA & 65 & 65 & 80 \\
\hline 3 & ANGGRAENI SIWI HAPSARI & 75 & 75 & 75 \\
\hline 4 & ANISA FAUJIA & 65 & 65 & 75 \\
\hline 5 & AR-RAFI RAHADIAN & 65 & 65 & 80 \\
\hline 6 & DEA HIMALIA PUTRI & 75 & 75 & 75 \\
\hline 7 & DINDA FALAIZA HARDWITA & 65 & 65 & 85 \\
\hline 8 & FAHRI DEAN ALVITO & 70 & 75 & 95 \\
\hline 9 & FARHAN BAROO ROZZAN & 70 & 75 & 80 \\
\hline 10 & FAUZI IKHSAN & 75 & 75 & 85 \\
\hline 11 & FIRIYAL CHASNA SEFIA PUTRI & 65 & 65 & 85 \\
\hline 12 & $\begin{array}{l}\text { FITROH AGUNG DIMAS } \\
\text { TETUKO }\end{array}$ & 65 & 75 & 85 \\
\hline 13 & JIHAN ALFIRA FITRIANA & 75 & 75 & 90 \\
\hline 14 & M. RAMANDA PUTRA & 65 & 65 & 80 \\
\hline 15 & $\begin{array}{l}\text { MADYA RAHMANDA } \\
\text { WANANTA }\end{array}$ & 75 & 75 & 80 \\
\hline 16 & MERI ANDANI & 65 & 75 & 80 \\
\hline
\end{tabular}




\begin{tabular}{|l|l|c|c|c|}
\hline 17 & $\begin{array}{l}\text { MUHAMMAD ABIZAR RIZKY } \\
\text { PUTRA }\end{array}$ & 65 & 65 & 80 \\
\hline 18 & REGITA AYUNI MUTHIA CANSA & 75 & 80 & 90 \\
\hline Jumlah & 1235 & 1285 & 1475 \\
\hline Rata -rata & 71.11 & 75,00 & 81,94 \\
\hline Persentase ketuntasan & $34 \%$ & $61 \%$ & $100 \%$ \\
\hline Jumlah ketuntasan & 6 & 11 & 18 \\
\hline Jumlah ketidaktuntasan & 12 & 7 & 0 \\
\hline Nilai tertinggi & 75 & 80 & 95 \\
\hline Nilai terendah & 60 & 65 & 75 \\
\hline
\end{tabular}

Dari data tersebut dapat disimpulkan bahwa terjadi peningkatan hasil belajar yaitu dari Pra siklus sebesar 71,11 yaitu 34\% yang diantarannya 6 tuntas dan 12 tidak tuntas dan 75,00 yaitu 61\% diantaranya 11 tuntas dan 7 tidak tuntas pada siklus I menjadi 81,94 yaitu 100\%,18 tuntas semua pada siklus II. Nilai rata-rata yang dicapai pada siklus II sebesar 81,94 menunjukan bahwa telah melampaui KKM yaitu 75

\section{KESIMPULAN}

Berdasarkan hasil penelitian dan pembahasan dapat disimpulkan bahwa penerapan metode demonstrasi dapat meningkatkan hasil belajar Pendidikan Agama Islam pada materi Pengurusan jenazah di kelas XI IPA3 pada tahun ajaran 2019/2020 dan mempermudah guru dalam mencapai tujuan belajar yang diinginkan. Hal ini dibuktikan dari peningkatan hasil rata-rata dari sebelum diterapkan metode Demonstrasi atau pra siklus sampai siklus II. Pada pra siklus nilai rata-rata yaitu 71,11. Nilai rata-rata tersebut meningkat pada siklus I yaitu 75,00 dan pada siklus II nilai rata-ratanya yaitu 81,94. Apabila dilihat dari perolehan nilai tertiggi pada setiap siklusnya juga mengalami peningkatan. Pada pra siklus nilai tertinggi 75 , pada siklus I nilai tertinggi meningkat menjadi 80, dan pada siklus II nilai tertinggi meningkat menjadi 95. Persentase ketuntasan belajar peserta didik juga mengalami peningkatan yaitu pada pra siklus yang tuntas hanya $34 \%$, pada siklus I meningkat menjadi $61 \%$, dan pada siklus II meningkat menjadi $100 \%$. Pada siklus II semua peserta didiksudah mencapai nilai KKM. Oleh karena itu Penelitian Tindakan Kelas ini dinyatakan berhasil.

\section{DAFTAR PUSTAKA}


Arikunto, Suharsimi. 2007. Prosedur Penelitian Suatu Pendekatan Praktik. Jakarta: Rineka Cipta.

Arikunto, Suharsimi. 2010. Prosedur Penelitian Suatu Pendekatan Praktik. Jakarta: Rineka Cipta.

As'ad, H. Aly. 2007 terjemahan Ta'limul Muta'allim, (Bimbngan Bagi Penuntut Ilmu Pengetahuan) Kudus: Menara Kudus.

Depdiknas, 2003. Undang Undang Sisdiknas no 20. Jakarta: Sinar Grfika.

Djamarah, Syaiful. 2000. Strategi Belajar Mengajar. Jakarta: Rineksa Cipta.

Fathurrohman, Pupuh, 2007. Strategi Belajar Mengajar. Bandung: Refika Aditama.

Huda, Miftahul. 2013. Model-Model Pengajaran dan Pembelajaran. Yogyakarta: Pustaka Pelajar.

Kunandar. 2011. Langkah Mudah Penelitian Tindakan Kelas Sebagai Pengembangan Profesi Guru. Jakarta: Rajawali Pres.

Nasih, Ahmad Munjin \& Kholidah, Lilik Nur. 2009, Metode dan Teknik Pembelajaran Pendidikan Agama Islam, Bandung: PT Refika Aditama.

Roestiyah. 2001. Strategi Belajar Mengajar. Jakarta: Rineka Cipta.

Sanjaya, Wina. 2008. Strategi Pembelajaran Berorientasi Standar Proses Pendidikan. Jakarta: Prenada Media Group. 